\title{
Studying the effect of Dielectric Barrier Discharges on the Leukemia Blood Cells Using Digital Image Processing
}

\author{
Sabah N. Mazhir ${ }^{1}$, Alyaa H. Ali ${ }^{1}$, Farah W. Hadi ${ }^{1}$, Alaa N. Mazher ${ }^{2}$ \\ ${ }^{I}$ Department of Physics, College of science for women/ University of Baghdad/Iraq \\ ${ }^{2}$ Computer Science Department/ University of Technology
}

\begin{abstract}
In this research, Plasma physics and digital image processing technique are utilized. Dielectric Barrier Discharges (DBD) plasma at atmospheric pressure is used for the purpose of studying the plasma effect on the blood tissue, The first order statistical features are used to study the effect of plasma on the blood tissue. Different samples are used to reach the aim of this paper: the patients have leukemia and their leukocytes number is abnormal. By studying the results of statistical features (Energy, Mean, Entropy, Skewness, Kurtosis), it is concluded that the blood cells of the sample shows a good response to the cold plasma. So the plasma can be used as a treatment for the blood tissue for the persons with Leukemia.
\end{abstract}

Keywords: Cold Plasma, Dielectric Barrier Discharges, First-Order Statistics

\section{Introduction}

A plasma is a gas that have enough energy to ionize the important portion of its molecules or, atoms forming equal numbers of electrons and positive ions. Plasmas show some properties of gases, but unlike gases in being good electrical conductors and being affected by magnetic fields. Although there are free charges in plasmas, general the positive and negative charges recompense each other.plasmas are electrically neutral, whichknown as quasi-neutrality. Plasmas cover extensive range of temperatures, pressures, and electron densities.[1] plasma is utilized to treat products and surfaces to show their bio performance and, bioapplicability Consecutively, to utilize plasma for curative purposes. both atmospheric pressure and low-pressure plasmas can be utilized, for direct curative plasma applications only plasma atmospheric pressure sources can be utilized[2]. Atmospheric pressure cold plasma was the base of one of the mostpromising approaches of attaining a more supple, less expensive, reliable and incessant method of surface adjustment [3]. The plasma has a numerous properties such as the capability to kill bacteria competently with high velocity, Therefore, it convenient for the sterilization of surgical instruments, [4] removal of environmental and medical task [5, 6, $7,8]$. The utilize of physical plasmas for bio-decontamination just as first surgical plasma applications like argon-plasma coagulation $[9,10]$ are mostly based on fatal plasmaeffects on living systems. However, there is an extra massive potential of plasma application with low temperature for curative fields, which will be based on non- fatal, stimulatingplasma effects on living cells and tissue [8,11].

\section{Dielectric Barrier Discharges (DBDs)}

The discharge of the insulating barrier technique (DBD) are worked in a wide range of pressures and are usually utilized in, UV sources, ozone generators, and excimer lamps, plasma- aided burning, etc. The micro discharges happen as discharge columns in the discharge gap which also prevalence over the dielectric surface. The charge carriers left on the surface of the dielectric reduce the field force in the discharge gap and quench the discharge itself.[13] DBDs are gaining significance since they can kindle plasma directly on the body surface which is at floating potential. Other devices such as the Plason offer the so-called indirect treatment where the plasma is produced at a remote point, and the chemically-active type are transported to the vicinity of treated-substrate. Most of the active types are lost through transport as a result of chemical and physical processes like electron-ion recombination in the effluent. This disadvantage is overcome in the direct treatment using DBDs. One of the major issues when using DBDs for medical application is their inhomogeneity when operated in air at atmospheric-pressure as a result of the creation of micro discharges that are spatially and temporally distributed in the discharge gap. This phenomenon be consider as a feature of nonuniform treatment of the substrate. To overcome this, DBD operated using a nanosecond pulsed power supply has been shown to produce a homogeneous discharge $[14,15]$ which can display more uniform treatment of the substrate in bio-medical applications.A homogeneous or a uniform discharge, free of micro discharges is more appropriate for treatments the surface. In low-pressure conditions, gaining such a homogeneous discharge is not complex. However, such a discharge in air at atmospheric-pressure condition is not simple. based on the frequency of the applied voltage, type of dielectric, working gas, etc., DBDs which produce homogeneous volume discharge have been confirmed. Such homogenous DBDs at atmospheric-pressure, referred as Atmospheric-Pressure Glow Discharge, have been happen by using He [16], He-N2 gas mixture [17], N2 [18, 19], Ne-N2 and Ar-N2 [20], Ar [21]. 


\section{First-Order Statistics}

\section{Material Methods}

First-order statistics refer to the distributions probability of the values to each pixels.If that all pixels in an image represent samples from the identical distribution, then it is possible to pool the pixels from a single image to get an appraisal of first order statistics. First order statistical parameters are computed from the image intensity values without bearing in mind the pixel neighbor connection.[22]

1- mean and the standard deviation:- utilized to measure the prevalence of gray level values of the pixels within that region (Histogram).[23]

$x_{1}=\sum_{k=0}^{K-1} k H(k) \quad \ldots \ldots 1$
$\sigma=\sqrt{\sigma^{2}}=\sqrt{\sum_{k=0}^{K-1}\left(k-x_{1}\right)^{2} H(k)} \quad \ldots \ldots 2$

2- Variance:- is a measure of the histogram width that measures the aberration of gray levels from the Mean [23]

$\sigma^{2}=\sum_{k=0}^{k-1}\left(k-x_{1}\right)^{2} H(k) \quad \ldots \ldots 3$

3- skewness and kurtosis:- skewness indicates a measure of the degree of histogram asymmetry around the mean, and kurtosis measure the sharpness of histogram.[24]

$x_{4}=(\sigma)^{-a} \sum_{k=0}^{K-1}\left(k-x_{1}\right)^{a} H(k) \quad \ldots \ldots 4$
$x_{5}=(\sigma)^{-4} \sum_{k=0}^{K-1}\left(k-x_{1}\right)^{4} H(k) \quad \ldots \ldots 5$

4-Energy:- It s tells us something about how the gray levels are distributed [25] and gives indication about the regularity of the texture in the image, the high energy means that the texture is more regular.

Energy $=\sum_{k=0}^{K-1}[H(k)]^{2} \quad \ldots \ldots 6$

5- Entropy:- tells us how many bits are need to code the image data and given by[26,27]

Entropy $=-\sum_{k=0}^{K-1} H(k) \log _{2}[H(k)] \quad \ldots \ldots$

1. Blood Sample:

The blood samples are taken for different living patient with leukemia, some people their leukocytes number exceed (10000), while others their leukocytes number are less than (4000). The normal range of the leukocytes is between (4000_10000). In this research different samples were used to reach the aim of this paper: the patients have leukemia and their leukocytes number was abnormal. The search deals with these samples after the exposure them to the cold plasma which produce by dielectric barrier discharge for different time. studying the effect of cold plasma on the texture of blood samples. The exposure duration started from (20 sec) up to (40 $\mathrm{sec})$ the time increasing with different step. Images are taken for each sample during the time exposure. These images which are taken are illustrated in figure $(1,2)$. To enhance the obtained images a digital image processing is applied for the segmentation process in order to help in separate the glass of the slides which used to prepare the sample from the blood texture. The color image must be converted to the gray scale image in order to apply the segmentation process, also to study the texture response to the plasma. The threshold must apply to separated the background of the slides from the blood texture, then the co-occurrence matrix is applied to study the texture properties.

$B(X, Y)=\begin{array}{lll}1 & \text { If } & f(x, y)>T \\ 0 & \text { If } & f(x, y) \leq T\end{array}$

Where $T$ is a threshold value, $f(x, y)$ is the input image and $B(x, y)$ is the resulting image. The output is binary image with (0 and 1). Figures (1 and 2) show that. 


\section{Discussion And Conclusion}

Table (1) Figure (3) the value of energy with time exposure (20-40s), sample (1) show small response to the plasma exposure. Sample 2 and sample (4) energy value decrease with time exposure in the 28,30 second the sample shows increase in it energy value then its value return to decrease increase with time increase. Sample (3) the value of the energy decreases with increasing the time exposure to cold plasma down to $(35 \mathrm{sec})$ the value start to increase. Table (2) and Figure (4) sample (1) the mean value decrease with the time exposure to plasma in the $(28,30)$ second the response change from decreasing to increasing just in $(28,30 \mathrm{sec})$ and it turn to decreases, sample (1) has white blood cell (14.56). Sample (2) the mean value increase with increasing the exposure time to plasma, in the second $(28,30)$ the value of mean reverse in it response because the value change then the value of the mean decrease with time exposure so does sample ( 3 and 4). Table (3) and Figure (5) show the entropy curve, the value of entropy for sample (1) decrease with time increasing.In the $(28,30 \mathrm{sec})$ the value increase with time. Sample (2) with white blood cell (17.94) the value of entropy increase with time to $(28,30 \mathrm{sec})$ then the value return to decrease. So is sample (4) with white blood cell (18.67). Sample (3) with white blood cell (20.15) its value does not change with time exposure in $(28,30 \mathrm{sec})$ the value started to response. It increase with time. Table (4) and Figure (6) shows the skewness value. Its value shows response to the plasma effect skewness value as it shape change from the Gaussian distribution. Sheft to the left or right its show change in the texture of the blood. Table (5) and Figure (7) shows the kurtosis value it represented the flatness of the histogram as the value increase the response increase the curve become more flat.

\section{Conclusion}

The following points are concluded from this study:

1. Some of the blood cells which have leukemia with white blood cell (>10000) show response to the effect of plasma, this has been detect practically and by using the digital image processing.

2. The time exposure to cold plasma as the time increase the intensity of the image increase, and the texture shows more regularity and brightness this can be showing by increasing the mean value.

3. The energy value increased with increasing the time exposure. This is because the texture become more regular, as the entropy inversely proportion to the energy its value decrease.

4. The value of energy increase with increasing the value of white cell this is because the leukemia cell is more regular in it shape than the blood texture as the leukemia cell increase the energy value increase, so does the mean its value decrease with increasing the white cell, this is because the leukemia cell tend to be more dark than the other cell.

[1]. P.C. Kong and E. Pfender, "Plasma Processes," in Carbide, Nitride and Boride Materials-Synthesis and Processing, 1st edition, ed., A. W. Weimer (Chapman \& Hall, 1997), 359-383

[2]. $\quad$ K. D. Weltmann, TH. V. Woedtke, R. Brandenburg, and J. Ehlbeck, "Biomedical applications of atmospheric pressure plasma," Chem. Listy 102, 1450-1451, 2008.

[3]. S. Cheruthazhekatt, M. Černák, and P. Slavicek, "Gas plasmas and plasma modified materials in medicine," J Appl Biomed, 8, 5566, 2010.

[4]. I.E. Kieft, "Plasma Needle: exploring biomedical applications of non-thermal plasmas". Print service Technics Universities Eindhoven: 153.2005

[5]. A. Kojtari, U. K Ercan, J. Smith, G. Friedman, R. B. Sensenig, S. Tyagi, Suresh G Joshi, Hai-Feng Ji and Ari D Brooks, "Chemistry for Antimicrobial Properties of Water Treated With Non-Equilibrium Plasma", Nanomedicine Biotherapeutic Discovery 2013, 4:1.

[6]. D. I. Jang, S. B. Lee, ,c Y. S. Mok, D. L. Jang, " Disinfection of Escherichia Coli by Dielectric Barrier Discharge Plasma", International Journal of Chemical and Environmental Engineering . June 2013, Volume 4, No.3.

[7]. G.Alcantara E, López-Callejas R, Morales-Ramírez PR, Peña-Eguiluz R, Fajardo-Muñoz R, Mercado-Cabrera A, Barocio SR, Valencia-Alvarado R, Rodríguez-Méndez BG, Muñoz-Castro AE, de la Piedad-Beneitez A, Rojas-Olmedo IA. Accelerated mice skin acute wound healing in vivo by combined treatment of argon and helium plasma needle. Arch Med Res. 2013;3(3):169-177.

[8]. $\quad$ G. Fridman, Friedman G, Gutsol A, Shekhter AB, Vasilets VN, Fridman A," Applied Plasma Medicine" Plasma Processes Polym." 2008, 5:503-533

[9]. J. Raiser, M. Zenker, "Argon plasma coagulation for open surgical and endoscopic applications" J. Phys. D: Appl. Phys. 39, 3520 (2006).

[10]. Sabah N. Mazhir, A. H. Ali, N. H. Harb and F. W. Hadi, The Effect of Dielectric Barrier Discharge Plasma on Smear of Leukemia Blood Cells by Texture Analysis Images, Journal of Applied Sciences Research(JASR), 13( 3),2017.

[11]. E. Stoffels, "Tissue Processing" with Atmospheric Plasmas", Contribution Plasma Phys. 47, 40 (2007).

[12]. S.N. Mazhir, A. H. Ali, N. K. Abdalameer,and F. W. Hadi, "Studying the effect of Cold Plasma on the Blood Using Digital Image Processing and Images Texture analysis," International conference on Signal Processing, Communication, Power and Embedded System (SCOPES)-2016.

[13]. P. Awakowicz, R.Brinkmann Atmospheric-pressure dielectric barrier discharge (DBD) in air: Plasma characterisation for skin therapy, 2011.

[14]. H. Ayan, G. Fridman, A. F. Gutsol, V. N. Vasilets, A. Fridman, and G. Friedman. Nanosecond-pulsed uniform dielectric-barrier discharge. IEEE Transactions on Plasma Science, 36:504-508, 2008.

[15]. H. Ayan, D. Staack, G. Fridman, A. Gutsol, Y. Mukhin, A. Starikovskii, A. Fridman, and G. Friedman. Application of nanosecondpulsed dielectric barrier discharge for biomedical treatment of topographically non-uniform surfaces, J. Phys. D: Appl. Phys., 42:125202, 2009. 
[16]. S. Kanazawa, M. Kogoma, T. Moriwaki, and S. Okazaki. Stable glow plasma at atmospheric pressure, J. Phys. D: App. Phys., 21:838-840, 1988.

[17]. F. Massines and G. Gouda. A comparison of polypropylene-surface treatment by filamentary, homogeneous and glow discharges in helium at atmospheric pressure. J. Phys. D: App. Phys., 31:3411-3420, 1998.

[18]. N. Gherardi, G. Gouda, E. Gat, A. Ricard, and F. Massines. Transition from glow silent discharge to micro-discharges in nitrogen gas. Plasma Sources Sci. Tech., 9:340-346, 2000.

[19]. N. Gherardi and F. Massines. Mechanisms controlling the transition from glow silent discharge to streamer discharge in nitrogen. IEEE Transactions on Plasma Science, 29:536-544, 2001.

[20]. R. Brandenburg, Z. Navratil, J. Jansky, P. Stahel, D. Trunec, and H.-E. Wagner. The transition between different modes of barrier discharges at atmospheric pressure. J. Phys. D: App. Phys., 42:085208, 2009.

[21]. F. Massines, N. Gherardi, N. Naude, and P. Segur. Glow and townsend dielectric barrier discharge in various atmosphere. Plasma Physics and Controlled Fusion, 47:B577-B588, 2005.

[22]. S. Mazhir, "Studying The Effect of Cold Plasma on Living Tissues Using Images Texture analysis," Diyala Journal For Pure Science. vol. 13. No.2, 2017.

[23]. A. Namita, R. K. Agrawal, "First and Second Order Statistics Features for Classification of Magnetic Resonance Brain Images," Journal of Signal and Information Processing, 2012, 3, 146-153.

[24]. S. A. Resmi, T.Thomas, "Texture Description of low grade and high grade Glioma using Statistical features in Brain MRIs", Int. J. of Recent Trends in Engineering and Technology, Vol. 4, No. 3, Nov 2010, pp.27-33

[25]. Azeez, M. A., Mazhir, S. N., \& Ali, A. H. "Detection and Segmentation of Lung Cancer using Statistical Features of X-Ray Images," International Journal of Computer Science and Mobile Computing, Vol.4 Iss.2, 307-313, 2015.

[26]. S. Rajput, and S. R. Suralkar, "Comparative Study of Image Enhancement Techniques". International Journal of Computer Science and Mobile Computing. Vol.2, No.1, PP: 11-21, 2013.

[27]. Azeez, M. A., Ali, A. H., Mazhir, A. N., \& Mazhir, S. N."Detection and segmentation of lung disease using Law Mask with Watershed on X-ray images," International Journal of Scientific \& Engineering Research, Vol. 6, Issue 3, March-2015 .

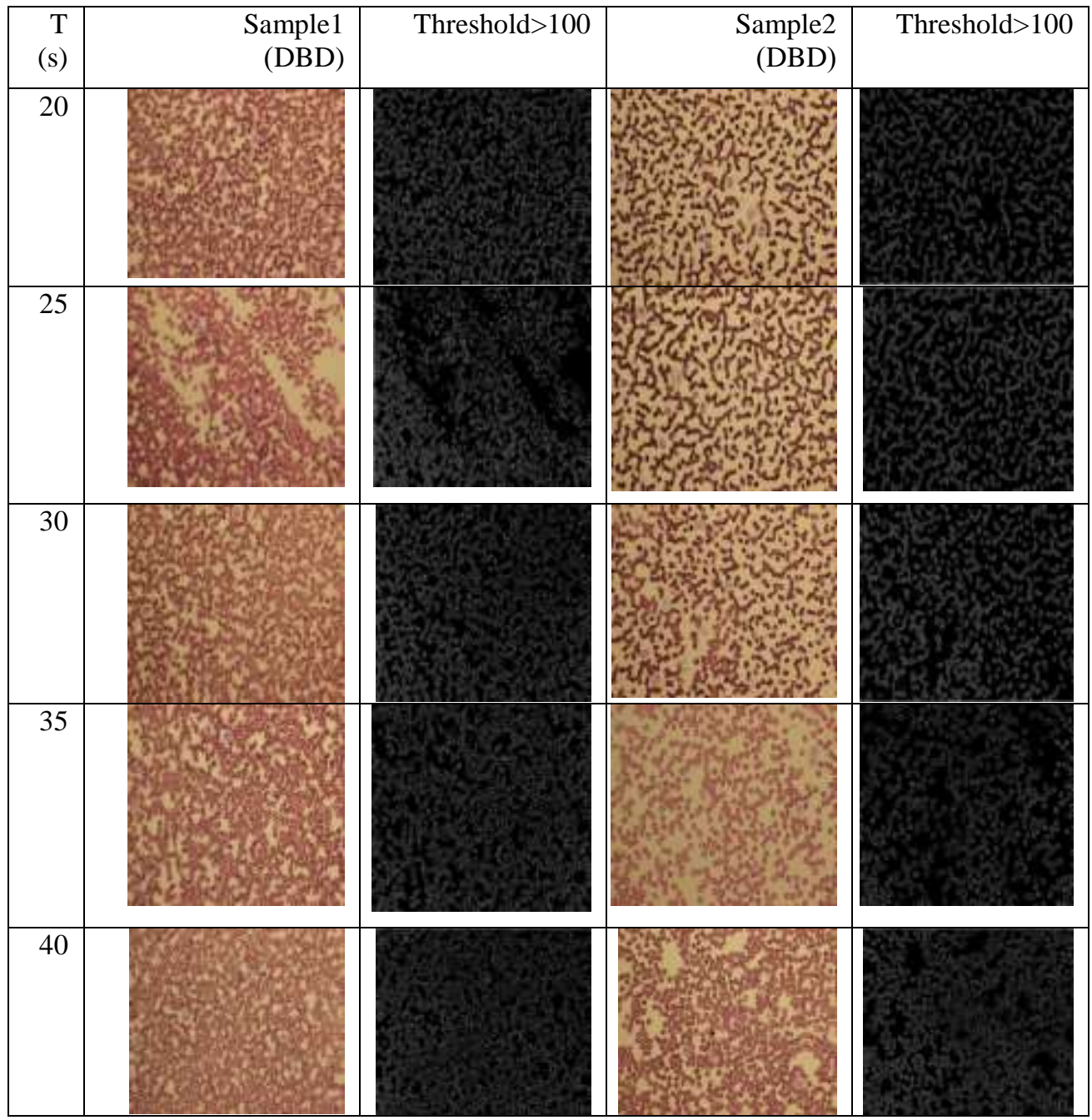

Figure (1) Shows the blood samples images (patient with leukemia), and the thresholding image in which Threshold $>100$. 
Studying the effect of Dielectric Barrier Discharges on the Leukemia Blood Cells Using Digital

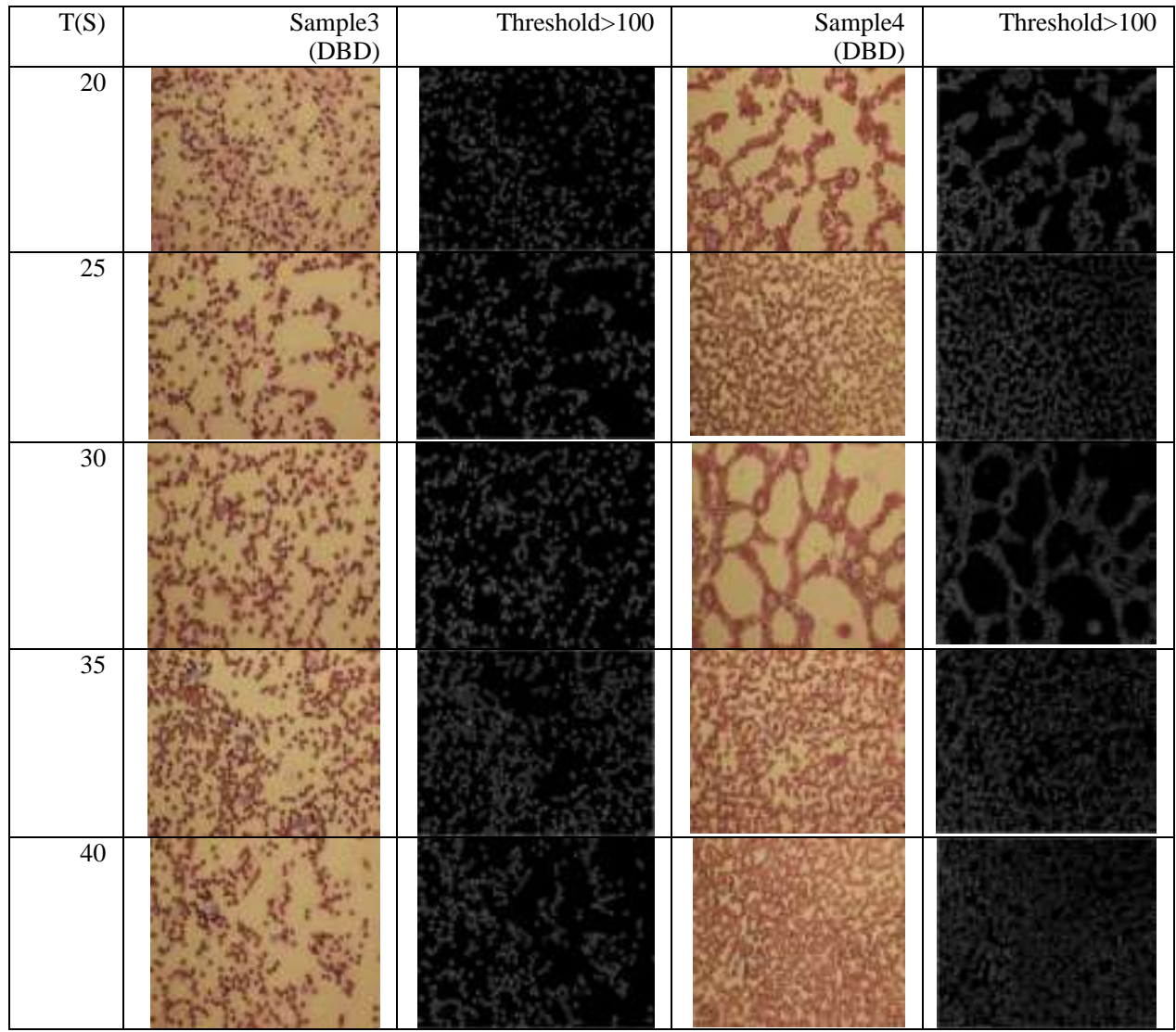

Figure (2) Shows the blood samples images (patient with leukemia), and the thresholding image in which Threshold > 100.

Table (1) the energy value for Blood samples.

\begin{tabular}{|l|l|l|l|l|}
\hline $\mathrm{T}(\mathrm{s})$ & sample1 & sample2 & Sample3 & Sample4 \\
\hline Count of white & \multicolumn{1}{|c|}{14.56} & & & \multicolumn{2}{|c|}{20.15} \\
\hline 20 & & & & \\
\hline 23 & 0.48 & 0.4897 & 0.6137 & 0.7165 \\
\hline 25 & 0.51402 & 0.4618 & 0.56258 & 0.70756 \\
\hline 28 & 0.5367 & 0.4432 & 0.5285 & 0.7016 \\
\hline 30 & 0.52332 & 0.47008 & 0.60164 & 0.6704 \\
\hline 33 & 0.5144 & 0.488 & 0.6504 & 0.6496 \\
\hline 35 & 0.52388 & 0.60584 & 0.62292 & 0.60364 \\
\hline 38 & 0.5302 & 0.6844 & 0.6046 & 0.573 \\
\hline 40 & 0.53518 & 0.57844 & 0.59236 & 0.6486 \\
\hline
\end{tabular}

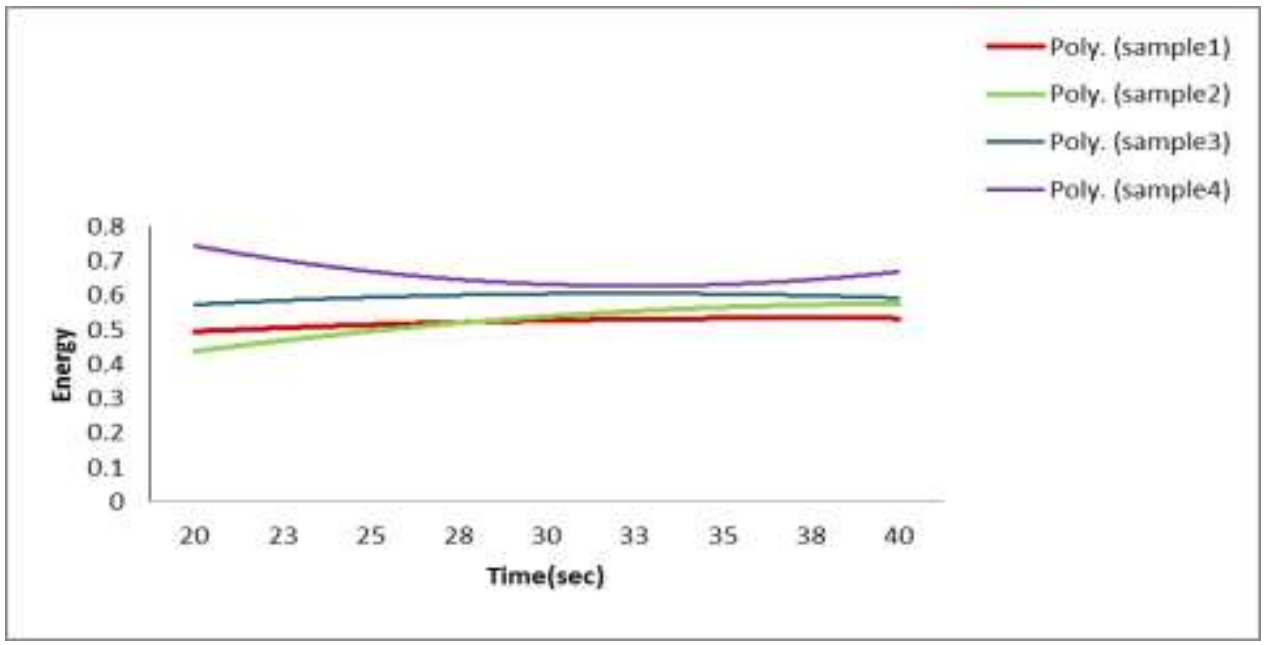

Figure (3) shows energy values as a function of time for(S1,S2,S3,S24) 
Table (2) the mean value for Blood samples.

\begin{tabular}{|l|l|l|l|l|}
\hline $\mathrm{T}(\mathrm{s})$ & sample1 & sample2 & Sample3 & Sample4 \\
\hline $\begin{array}{l}\text { Count of white } \\
\text { blood cell }\end{array}$ & 14.56 & 17.94 & 18.67 & 20.15 \\
\hline 20 & 23.6823 & 16.9984 & 17.344 & 10.9709 \\
\hline 23 & 22.19742 & 18.8389 & 19.39066 & 11.1593 \\
\hline 25 & 21.2075 & 20.0659 & 20.7551 & 11.2849 \\
\hline 28 & 21.77702 & 19.98208 & 17.49164 & 12.92236 \\
\hline 30 & 22.1567 & 19.9262 & 15.316 & 14.014 \\
\hline 33 & 21.80378 & 16.76708 & 16.95016 & 15.64978 \\
\hline 35 & 21.5685 & 14.661 & 18.0396 & 16.7403 \\
\hline 38 & 21.53574 & 18.78618 & 18.23898 & 13.8006 \\
\hline 40 & 21.5139 & 21.5363 & 18.3719 & 11.8408 \\
\hline
\end{tabular}

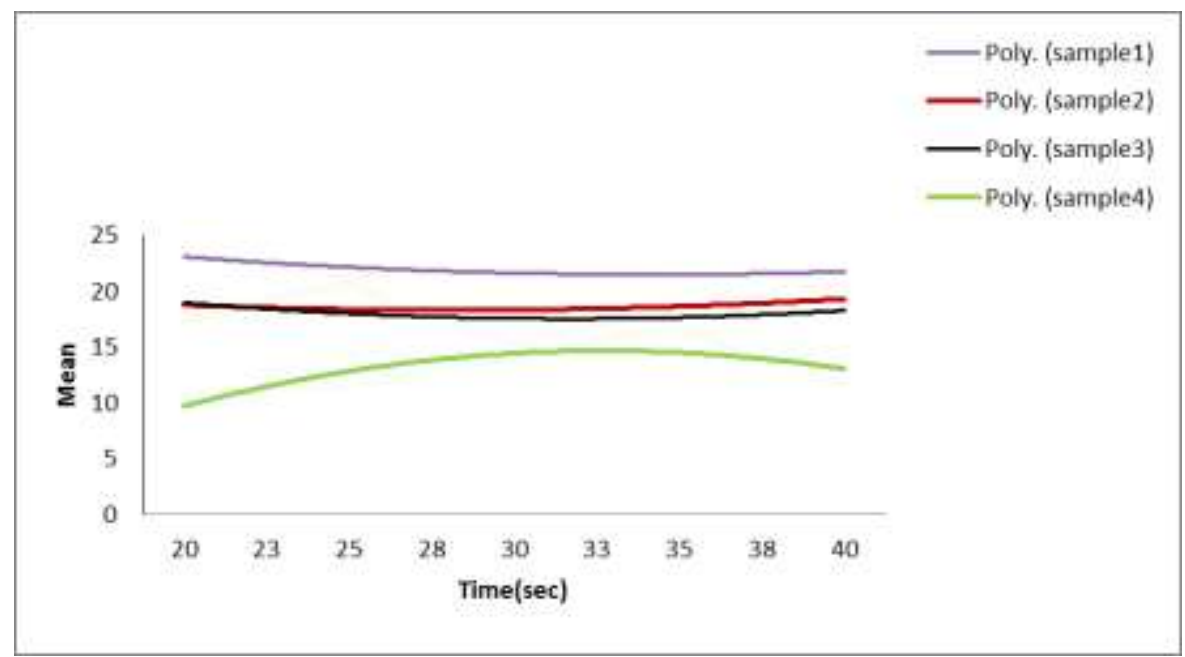

Figure (4) shows mean values as a function of time for(S1,S2,S3,S4)

Table (3) the entropy for Blood samples.

\begin{tabular}{|l|l|l|l|l|}
\hline $\mathrm{T}(\mathrm{S})$ & sample1 & sample2 & Sample3 & Sample4 \\
\hline $\begin{array}{l}\text { Count of white } \\
\text { blood cell }\end{array}$ & 14.56 & 17.94 & 18.67 & 20.15 \\
\hline 20 & 0.3958 & 0.3675 & 0.2947 & 0.2127 \\
\hline 23 & 0.37264 & 0.38628 & 0.3298 & 0.2151 \\
\hline 25 & 0.3572 & 0.3988 & 0.3532 & 0.2167 \\
\hline 28 & 0.36752 & 0.38248 & 0.30538 & 0.24394 \\
\hline 30 & 0.3744 & 0.3716 & 0.2735 & 0.2621 \\
\hline 33 & 0.37068 & 0.29708 & 0.29576 & 0.2921 \\
\hline 35 & 0.3682 & 0.2474 & 0.3106 & 0.3121 \\
\hline 38 & 0.35104 & 0.32612 & 0.3193 & 0.2581 \\
\hline 40 & 0.3396 & 0.3786 & 0.3251 & 0.2221 \\
\hline
\end{tabular}

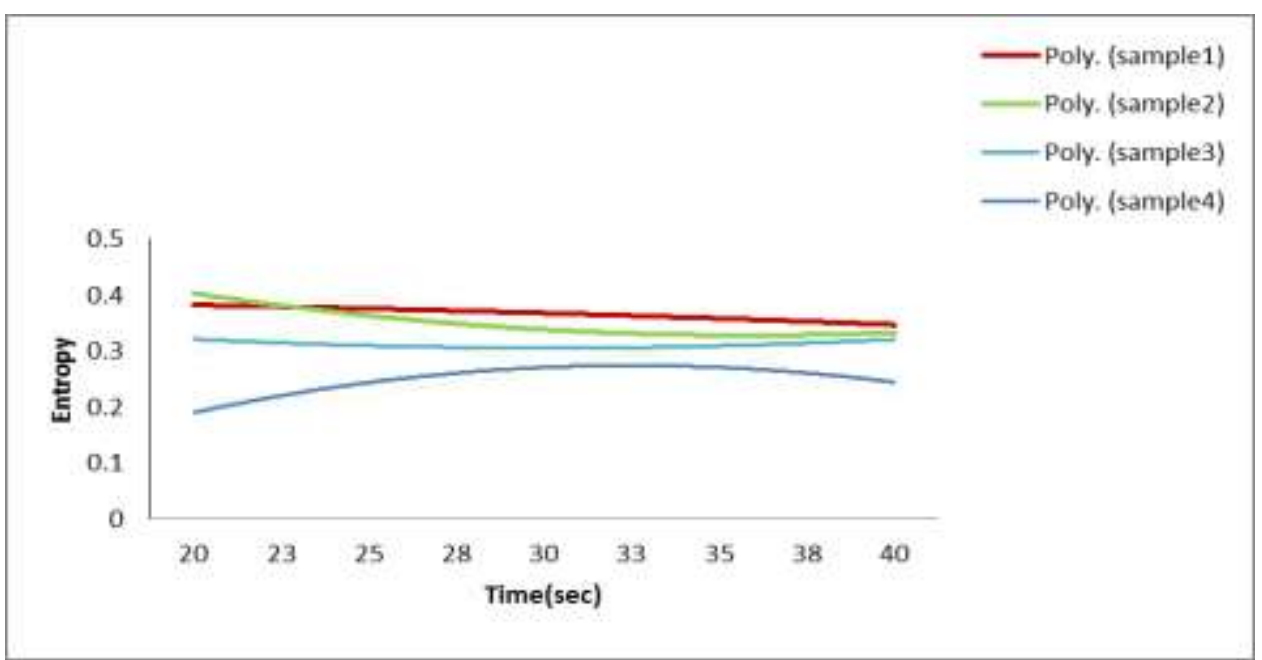

Figure (5) shows entropy values as a function of time for(S1,S2,S3,S4) 
Table (4) the skewness value for Blood samples.

\begin{tabular}{|l|l|l|l|l|}
\hline $\mathrm{T}(\mathrm{s})$ & sample1 & sample2 & Sample3 & Sample4 \\
\hline $\begin{array}{l}\text { Count of white } \\
\text { blood cell }\end{array}$ & 14.56 & 17.94 & 18.67 & 20.15 \\
\hline 20 & $4.05 \mathrm{E}-05$ & $1.05 \mathrm{E}-04$ & $6.63 \mathrm{E}-05$ & $1.84 \mathrm{E}-04$ \\
\hline 23 & $4.43 \mathrm{E}-05$ & $8.58 \mathrm{E}-05$ & $5.72 \mathrm{E}-05$ & $1.80 \mathrm{E}-04$ \\
\hline 25 & $4.68 \mathrm{E}-05$ & $7.32 \mathrm{E}-05$ & $5.11 \mathrm{E}-05$ & $1.77 \mathrm{E}-04$ \\
\hline 28 & $4.52 \mathrm{E}-05$ & $6.88 \mathrm{E}-05$ & $7.13 \mathrm{E}-05$ & $1.37 \mathrm{E}-04$ \\
\hline 30 & $4.42 \mathrm{E}-05$ & $6.59 \mathrm{E}-05$ & $8.48 \mathrm{E}-05$ & $1.10 \mathrm{E}-04$ \\
\hline 33 & $4.51 \mathrm{E}-05$ & $7.83 \mathrm{E}-05$ & $7.02 \mathrm{E}-05$ & $9.46 \mathrm{E}-05$ \\
\hline 35 & $4.58 \mathrm{E}-05$ & $8.65 \mathrm{E}-05$ & $6.05 \mathrm{E}-05$ & $8.41 \mathrm{E}-05$ \\
\hline 38 & $4.53 \mathrm{E}-05$ & $6.40 \mathrm{E}-05$ & $6.12 \mathrm{E}-05$ & $1.26 \mathrm{E}-04$ \\
\hline 40 & $4.50 \mathrm{E}-05$ & $4.90 \mathrm{E}-05$ & $6.16 \mathrm{E}-05$ & $1.55 \mathrm{E}-04$ \\
\hline
\end{tabular}

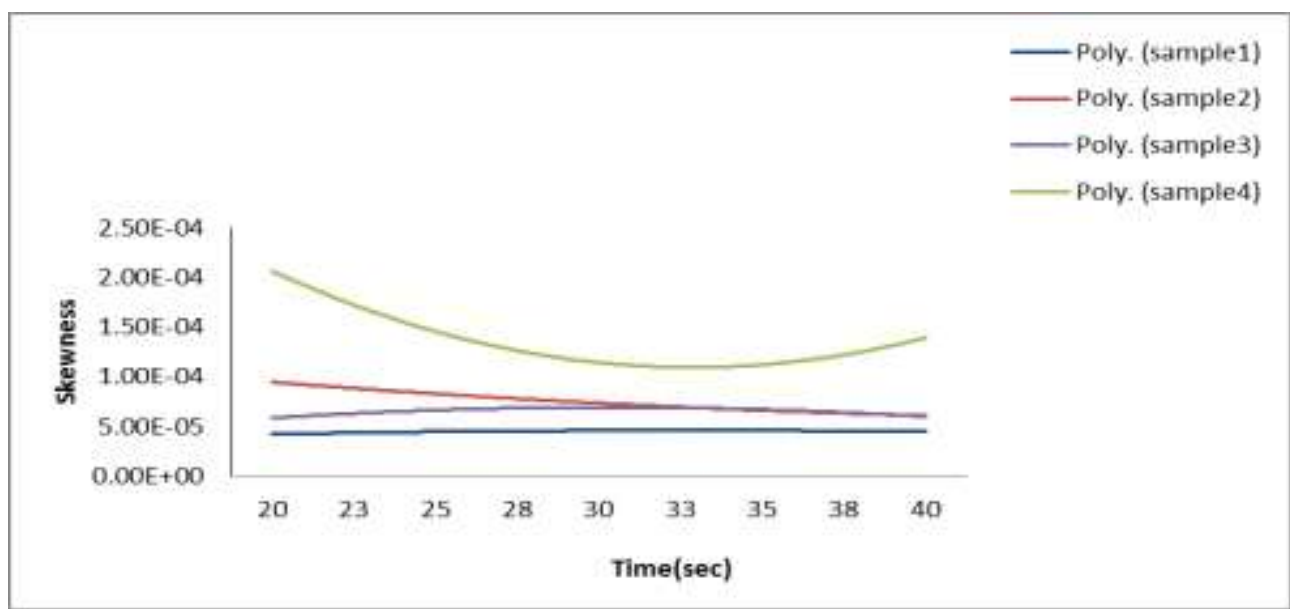

Figure (6) shows skewness values as a function of time for(S1,S2,S3,S4)

Table (5) the kurtosis value for Blood samples.

\begin{tabular}{|l|l|l|l|l|}
\hline $\mathrm{T}(\mathrm{s})$ & sample1 & sample2 & Sample3 & Sample4 \\
\hline $\begin{array}{l}\text { Count of white } \\
\text { blood cell }\end{array}$ & 14.56 & 17.94 & 18.67 & 20.15 \\
\hline 20 & $3.15 \mathrm{E}-08$ & $1.41 \mathrm{E}-07$ & $6.32 \mathrm{E}-08$ & $2.97 \mathrm{E}-07$ \\
\hline 23 & $3.55 \mathrm{E}-08$ & $1.06 \mathrm{E}-07$ & $5.19 \mathrm{E}-08$ & $2.88 \mathrm{E}-07$ \\
\hline 25 & $3.81 \mathrm{E}-08$ & $8.24 \mathrm{E}-08$ & $4.43 \mathrm{E}-08$ & $2.82 \mathrm{E}-07$ \\
\hline 28 & $3.64 \mathrm{E}-08$ & $7.41 \mathrm{E}-08$ & $7.25 \mathrm{E}-08$ & $1.96 \mathrm{E}-07$ \\
\hline 30 & $3.53 \mathrm{E}-08$ & $6.86 \mathrm{E}-08$ & $9.13 \mathrm{E}-08$ & $1.38 \mathrm{E}-07$ \\
\hline 33 & $3.65 \mathrm{E}-08$ & $8.30 \mathrm{E}-08$ & $6.94 \mathrm{E}-08$ & $1.12 \mathrm{E}-07$ \\
\hline 35 & $3.72 \mathrm{E}-08$ & $9.26 \mathrm{E}-08$ & $5.49 \mathrm{E}-08$ & $9.49 \mathrm{E}-08$ \\
\hline 38 & $3.64 \mathrm{E}-08$ & $6.22 \mathrm{E}-08$ & $5.64 \mathrm{E}-08$ & $1.75 \mathrm{E}-07$ \\
\hline 40 & $3.59 \mathrm{E}-08$ & $4.19 \mathrm{E}-08$ & $5.74 \mathrm{E}-08$ & $2.28 \mathrm{E}-07$ \\
\hline
\end{tabular}

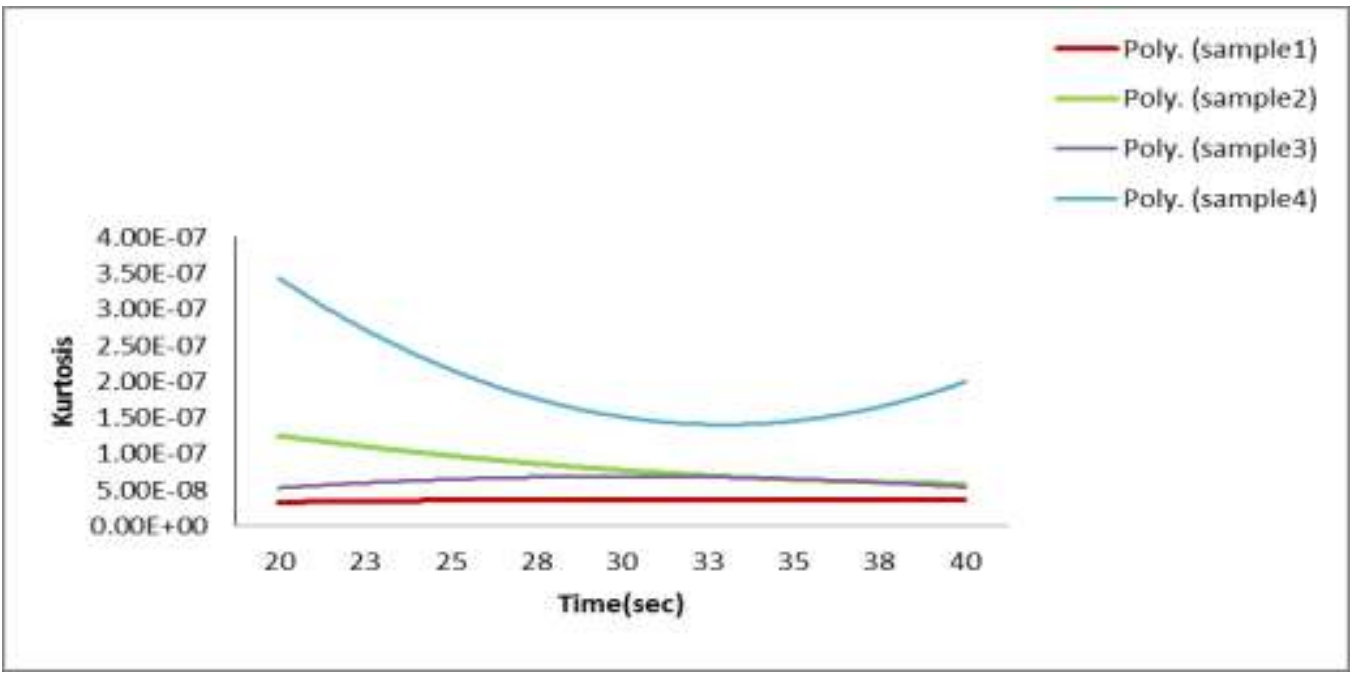

Figure (7) shows kurtosis values as a function of time for(S1,S2,S3,S4) 